\title{
Management of stillbirths: an observational analysis at a rural tertiary care centre in Kerala, India
}

\author{
Ajini K. K. ${ }^{1 *}$, Reena R. P. ${ }^{1}$, Radha K. R. ${ }^{2}$
}

${ }^{1}$ Department of Obstetrics and Gynecology, Government Medical College, Thrissur, Kerala, India
${ }^{2}$ Department of Obstetrics and Gynecology, Government Medical College, Ernakulam, Kerala, India

Received: 27 January 2019

Accepted: 05 March 2019

\section{*Correspondence:}

Dr. Ajini K. K.,

E-mail: ajinivijoy@gmail.com

Copyright: () the author(s), publisher and licensee Medip Academy. This is an open-access article distributed under the terms of the Creative Commons Attribution Non-Commercial License, which permits unrestricted non-commercial use, distribution, and reproduction in any medium, provided the original work is properly cited.

\section{ABSTRACT}

Background: Stillbirth is a distressing event, both for the expecting mother and the obstetrician. Several maternal, social and circumstantial factors influence its occurrence. These women with intrauterine fetal death need to be treated in a considerate manner. Our aim was to analyse different methods of induction, management of labour and their outcomes in women with antepartum fetal demise.

Methods: All women admitted to a tertiary care centre with intrauterine fetal death after 22 weeks during the study period of 24 months were recruited. Maternal sociodemographic characteristics and relevant investigations were studied. Induction of labour was achieved with mechanical and pharmacological methods. Stillborn babies, placentae and umbilical cord were examined after delivery.

Results: There were 175 women with IUFD admitted during the study period. The stillbirth rate was 38.6 per1000 live births. 148 women $(84.57 \%)$ required induction of labour while16 women had spontaneous onset of labour. Among the 44 women with previous Cesarean section, 11 underwent elective Cesarean section. 19 women (57.6\%) out of 33 cases of trial of labour after Cesarean had a successful vaginal delivery. There were 2 cases of rupture uterus and 10 women required ICU admissions. Intrauterine growth restriction was the leading cause of stillbirth (41.8\%) followed by hypertensive disorders $(27.7 \%)$.

Conclusions: Present study has shown that vaginal birth can be achieved in most women with mechanical and pharmacological methods of induction within a reasonable period of time.

Keywords: Management of labour, Misoprostol, Previous caesarean, Stillbirths

\section{INTRODUCTION}

Stillbirth can be a devastating experience to the bereaved parents and family members. It can result in immediate and long-lasting psychological effects on the mother. The health care providers too, have to overcome a complex situation where a probable cause and contributory factors involved have to be identified and a suitable method of termination of pregnancy suggested. The reported incidence of stillbirths varies significantly between studies from different countries and depends on the definitions used. Out of a global estimate of 2.6 million stillbirths in 2015 with a stillbirth rate of 18.4 per 1000 births, majority occurred in the developing world and India accounted for the highest number of stillbirths. ${ }^{1}$ A wide range of maternal, social and circumstantial factors influence its occurrence.

Stillbirth (SB) is defined as a fetus with no signs of life prior to the complete expulsion or extraction from its mother, and after a pre-defined duration of gestation; after delivery it is confirmed that the fetus does not 
show any evidence of life and cannot be resuscitated. The minimum gestational age cut-off defining stillbirths vs. miscarriage generally varies from 20 to 28 weeks of gestation based on available medical care and health infrastructure. $^{2}$ The Brighton Collaboration Stillbirth Working group recommends making explicit a working definition of SB to capture all events, for example early (after 22 weeks) vs late (after 28 weeks) stillbirths. ${ }^{3}$ Stillbirths are referred to as antepartum stillbirths when it occurs before the onset of labour and intrapartum stillbirth after the onset of labour.

In the stressful situation of an intrauterine fetal death (IUFD), the options are either to await the onset of spontaneous labour or to induce labour. It may take several weeks for spontaneous expulsion. Retention of the fetus can be associated with emotional distress, intrauterine infection if membranes are ruptured and a time related risk of consumptive coagulopathy. Management of labour and finding the cause of fetal death is difficult.

This becomes more difficult when intrauterine fetal death occurs in a woman with a prior Cesarean delivery. The surgical methods of inductions may precipitate infection. Oxytocin induction is more likely to fail as the uterus is less sensitive to oxytocin remote from term. Occasionally, mechanical methods using a cervical balloon, and rarely, surgical procedures such as hysterectomy and Cesarean section may be needed. Though both Mifepristone-Misoprostol Combination Regimen and Misoprostol-alone Regimen for induction of labour in IUFD have been recommended by different international associations, there is no consensus regarding the ideal regimen. ${ }^{4,5}$

The purpose of this study was to analyze methods of induction, management of labour and their outcomes in women with antepartum fetal demise.

\section{METHODS}

This was a cross sectional study done in the Department of Obstetrics and Gynecology at Government Medical College, Thrissur, Kerala, India. All women with antepartum intrauterine death at or more than 22 weeks (fetal weight 500 gms or more if gestational age was not known) admitted to our Hospital between March 2014 to February 2016 were recruited for the study.

\section{Inclusion criteria}

- All consecutive women with an IUFD consenting to take part in the study were included.

\section{Exclusion criteria}

- Women with a history of attempted feticide or admitted after having delivered a stillborn elsewhere, were excluded.
The study protocol was accepted by the Institutional Review Board. Informed consent was obtained from all the subjects. The diagnosis of intrauterine death was confirmed on ultrasound by the absence of fetal heart pulsation. Gestational age was confirmed by either reliable dates or a first trimester ultrasound. When gestational age was not known, stillborn babies weighing more than 500gms when delivered. Maternal demographic data, medical and surgical history, and obstetric history were collected using a structured proforma. Women were examined and relevant investigations were done. Cervical favourability was assessed using the Bishop's score. The mode of induction of labour was decided upon by the previous obstetric history and Bishop's score. Induction of labour with mifepristone-misoprostol combination regimen was as follows. A single oral dose of $200 \mathrm{mg}$ mifepristone was given initially. Oral misoprostol, $100 \mu \mathrm{g}$, was given 48 hours later for gestations between 22 and 34 weeks. Following administration of the first dose, a further two

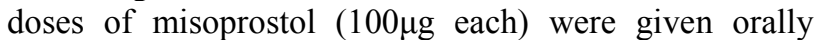
every 6 hours. For gestations over 34 weeks, $50 \mu \mathrm{g}$ of misoprostol was administered in a similar manner. If the first course was unsuccessful, the woman was not given any further labour inducing agents for the next 24 hours. A second course was then administered starting with the first oral dose of misoprostol. Misoprostol alone regimen was used in women who were multiparous or when the cervix was favourable. In women with a previous cesarean, Foley catheter with Extra Amniotic Saline (EAS) Infusion for cervical ripening was used followed by Prostaglandin E2 gel or misoprostol if required. Augmentation of labour was done with oxytocin if needed. Repeat Cesarean delivery was done electively when trial was contraindicated. Subsequent to induction, uterine contractions, pulse, blood pressure, temperature and systemic symptoms were monitored. Uterine tachysystole ( six contractions in a 10-minute period for two consecutives 10-minute periods) and hyper tonicity (a single uterine contraction with a duration of more than two minutes) were watched out for and recorded. Maternal complications such as uterine rupture, postpartum endometritis and requirement for blood and blood component therapy were noted. After delivery, the stillborn baby, placenta and umbilical cord were examined and recorded.

\section{Statistical analysis}

Data were analyzed using SPSS 10.1 for statistical Package (SPSS Inc. Chicago, Illinois, USA). Variables that were normally distributed are presented as means with standard deviations and ranges. The induction delivery interval was used as the dependent variable.

\section{RESULTS}

There were 203 stillbirths and 5264 total live births during the study period of 24 months.175 cases of stillbirths that fulfilled the criteria were recruited. 
Stillbirth rate was 38.6 per 1000 live births. Demographic and obstetric characteristics are presented in Table 1.

Table 1: Demographic and obstetric characteristics of the women with IUFD.

\begin{tabular}{|l|l|}
\hline Characteristics & No. \\
\hline Rural population & $81.36 \%$ \\
\hline Unbooked status & $12.42 \%$ \\
\hline Low socioeconomic status & $89.83 \%$ \\
\hline Age in years & $27.28 \pm 4.27$ \\
\hline Parity (multi and primi) & $59.32 \& 40.68 \%$ \\
\hline Gestation at induction in weeks & $30.96 \pm 3.75$ \\
\hline Bishop's score & $4(2-9)$ \\
\hline Birth weight (g) & $1311.77 \pm 546.9$ \\
\hline Induction to delivery interval (hours) & $18.54 \pm 6.08$ \\
\hline
\end{tabular}

Categorical variables are presented as $\mathrm{n} \%$, continuous variables as mean $\pm \mathrm{SD}$ and median [range]. Sixteen women (9.69\%), including 5 women with prior Caesarean section had spontaneous onset of labour while awaiting investigation results and arrangement of crossmatched blood. 148 women $(84.57 \%)$ required induction of labour. The induction to delivery interval reflects the time interval between first doses of misoprostol to expulsion of fetus. The induction delivery interval varied from 5 hours 43 minutes to 42 hours 25 minutes with a mean of 18 hours 54 minutes \pm 6 hours 8 minutes. In women (120) with an unscarred uterus, Mifepristone Misoprostol combination regimen was used for induction of labour in $72(60 \%)$ subjects, while Misoprostol alone was the mode of induction in $48(40 \%)$ women. All women had successful induction of labour, requiring misoprostol doses ranging from 50 to $400 \mu \mathrm{g}$. The mean dose of misoprostol required to achieve established labour in pregnancies above 34 weeks was $125 \mu \mathrm{g}$ while that for gestational age between 22 and 34 weeks was $250 \mu \mathrm{g}$. Table 2 shows the relationship between gestational age at induction and the dose of misoprostol required to establish labour. Twenty-eight women $(16.96 \%)$ required augmentation with oxytocin for inefficient uterine contractions.

Table 2: Relationship between dosage requirement of Misoprostol and gestational age.

\begin{tabular}{|l|l|l|}
$\begin{array}{l}\text { Gestational age } \\
\text { (weeks) }\end{array}$ & $\begin{array}{l}\text { Dosage range } \\
(\mu g)\end{array}$ & $\begin{array}{l}\text { Mean dosage } \\
(\mu g)\end{array}$ \\
\hline $22-34$ & $100-400$ & $250 \pm 75.6$ \\
\hline$>34$ & $50-250$ & $125 \pm 45.4$ \\
\hline
\end{tabular}

Tachysystole or hypertonicity did not occur in any of these women. The most common side effects were cramping, nausea, vomiting, diarrhoea, pyrexia and shivering. Twenty-one women required analgesia during labour. The mode of management of labour in IUFD is shown in Figure 1. There were 44 women (24.8\%) with prior Caesarean delivery and antepartum stillbirth. Among them $33(75 \%)$ were given trial of labour after Cesarean section (TOLAC), while 11 women underwent elective repeat cesarean section. The indications for repeat caesarean section included placenta praevia in 4 women, abruptio placentae in 2, previous two or more cesarean sections in 2, suspected macrosomia in 1 subject and antepartum eclampsia in 2 women.

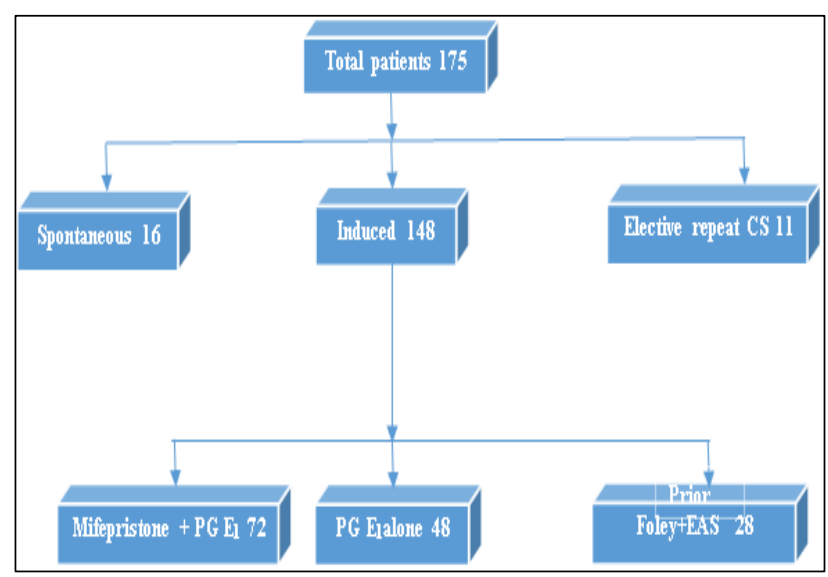

Figure 1: Mode of management of labour in IUFD.

Among the TOLAC group, 19 women (57.67\%) achieved successful VBAC (vaginal birth after Cesarean) when trial of labour was attempted, while14 (42.33\%) of them underwent repeat emergency sections. Mode of induction of labour in women with prior one Caesarean section is given in Table 3 .

Table 3: Mode of induction in previous caesarean with IUFD given TOLAC.

\begin{tabular}{|l|l|}
\hline $\begin{array}{l}\text { Mode of induction } \\
\text { Foley EAS + Mifepristone+ } \\
\text { Misoprostol }\end{array}$ & $\begin{array}{l}\text { No. of women with } \\
\text { previous CS and IUFD }\end{array}$ \\
\hline Foley EAS + misoprostol & $8(24.2 \%)$ \\
\hline Foley EAS + PGE 2 gel & $5(15.2 \%)$ \\
\hline Foley EAS alone & $3(9 \%)$ \\
\hline Spontaneous labour & $5(15.2 \%)$ \\
\hline Total & 33 \\
\hline
\end{tabular}

Foley catheter with extra amniotic saline infusion was used only in cases with prior CS. Two women with a previous cesarean delivery who underwent labour induction had rupture of the uterus. The women with uterine rupture had an average gestational age of 31.56 weeks and the average birth weight of their babies was 2034 grams. Both these women had labour induced with Foley + EAS insertion followed by prostaglandin $\mathrm{E}_{2}$ gel application in posterior fornix and labour augmentation with oxytocin. Both women had repair of the ruptured scar and bilateral tubal ligation. The mode of management of labour in IUFD with prior CS is shown in Figure 2. The rate of blood transfusion was $8 \%$. A total of $10(5.7 \%)$ women required ICU admissions for conditions like uncontrolled hypertension, HELLP syndrome and for hemodynamic monitoring. One woman in the induced group with an unscarred uterus 
required manual removal of retained placenta. Among the induced group with a scarred uterus, two women required hysterectomy for atonic postpartum haemorrhage (PPH) following Emergency Caesarean section. There were no maternal deaths in this cohort of patients.

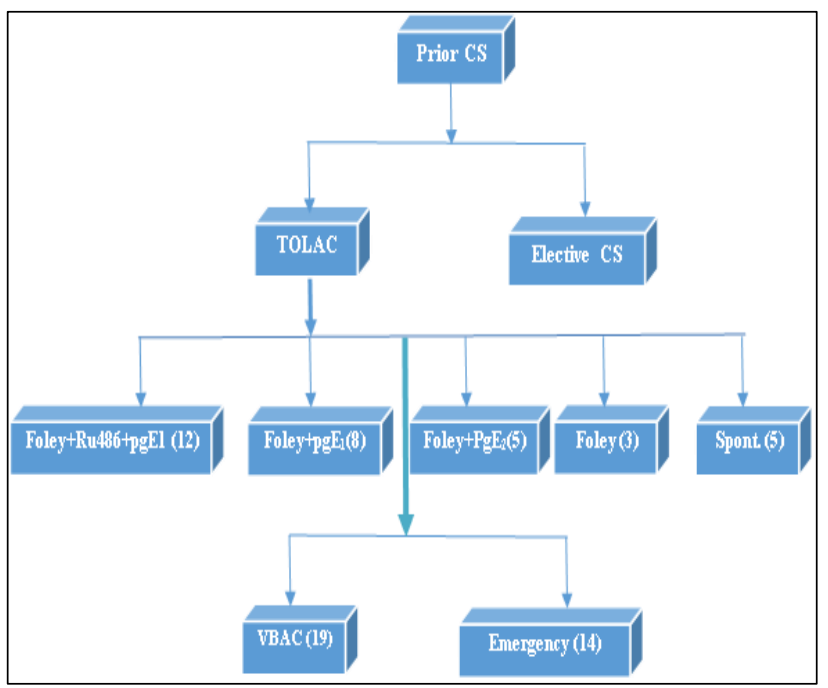

Figure 2: Mode of termination of IUFD in prior caesarean section.

There were $49(27.7 \%)$ women whose pregnancy was complicated by hypertension while $26(14.7 \%)$ women had Gestational Diabetes mellitus. Other pre-existing maternal diseases like thyroid disease, seizure disorder, chronic hypertension, renal disease and connective tissue disease were also present. The commonest cause for stillbirth was IUGR $(41.8 \%)$ followed by hypertensive disorders $(27.7 \%)$.

\section{DISCUSSION}

In the current study, a large majority $(84.57 \%)$ of women with an IUFD required induction of labour. Most of them received prostaglandin analogues along with mifepristone. A combination of mifepristone and misoprostol was a very effective and safe method of induction of labour in IUFD in present study. Most of these subjects had a successful induction resulting in vaginal delivery with few complications. The prolonged time interval from induction of labour to expulsion of the dead fetus are not acceptable to many women. The combined regimen of mifepristone with a prostaglandin analogue results in a synergistic effect. Uterine sensitivity to prostaglandins is known to increase with advancing gestation6. This predisposes women to develop tachysystole to uterotonic agents. Since authors used a reduced dose $(50 \mu \mathrm{g})$ for women more than 34 weeks gestational age, it did not have tachysystole or hypertonic uterine contractions in any of the present patients. Authors had limited the dose of misoprostol to a maximum of 4 doses in 24 hours with the fourth dose being given only to a very few women. Using mifepristone prior to misoprostol is of value in reducing the induction delivery interval as well as in the total dose of misoprostol required. Improved patient acceptability and reduced risk of introducing intrauterine infection are potential advantages of oral misoprostol over vaginal misoprostol. ${ }^{7}$ Authors had two cases of obstetric hysterectomies for atonic PPH and one woman needed manual removal of placenta. Present study population being from a tertiary care center included women with other comorbidities. Even though there were ICU admissions for uncontrolled hypertension, HELLP syndrome and hemodynamic monitoring, there were no maternal deaths. The ideal treatment regimen and optimum dosage for better management of IUFD is yet to be established. Surgical methods may invite infection. Oxytocin is less effective for induction of labour. ${ }^{8}$ RCOG recommends a combination of mifepristone and prostaglandin combination which is also endorsed by the NICE guidelines especially for late IUFD., ${ }^{4,5}$ WHO recommends oral or vaginal misoprostol for induction. ${ }^{9}$ The dosage regimens used in present study were most often mifepristone and misoprostol. The results of this study are similar to the findings in other reports. ${ }^{10}$

In present study, women with IUFD and prior cesarean section, trial of labour following induction with EAS instillation and prostaglandins was found to be effective. 33 women were given trial of labour. 28 of these women had induction of labour with mechanical and pharmacological methods while 5 women had spontaneous onset of labour. Authors could achieve successful vaginal delivery in $19(57.67 \%)$ of the 33 women with prior Caesarean who were given a trial. Authors had two cases of rupture uterus in the TOLAC group. The frequency of uterine rupture in this study of $3.56 \%$ is similar to the reported rates of uterine rupture in women with previous caesarean delivery who underwent induction of labour. ${ }^{11,12}$ In women with IUFD and prior caesarean delivery, prevention of maternal morbidity is important. Repeat caesarean delivery, in women who plan future pregnancies, may increase the risk of uterine rupture, placenta accreta and morbidity related to multiple abdominal surgeries. Women who deliver successfully vaginally have less postpartum discomfort, shorter hospital stay and shorter periods of disability than women who undergo repeated caesarean delivery. ${ }^{13}$

Growth restriction was the most common condition $(41.8 \%)$ associated with stillbirth in present study. Hypertensive disorders of pregnancy $(27.7 \%)$ was the second most significant condition associated with stillbirth followed by diabetes mellitus (14.7\%). Congenital malformations were present in $15 \%$ of cases. Most of these were due to open neural tube defects. Knowing the cause of stillbirth is very important for the management of future pregnancies. ${ }^{14}$ In the current study, psychological outcome was not addressed. It is well known that complex emotional factors are associated with fetal loss. The woman herself or her relatives are often not able to decide between induction and watchful expectancy because of the emotional impact of an IUFD. 
Once intrauterine death is confirmed, majority of women hope for expulsion of the dead fetus as early as possible. Hence induction of labour is often accepted. Late IUFD poses particular difficulties as it is sudden and unexpected. Women with a dead fetus in utero need an empathetic approach and every effort must be made to identify a cause for the IUFD. Counseling these women regarding future pregnancies may have to be based on these conclusions. The cross-sectional nature of data collection precludes recall bias. Ideally randomized controlled trials are needed to establish optimum dosage schedules of drugs used for induction. This may not be feasible following intrauterine death in view of the large number of patients required and the complexity of emotional factors associated.

\section{CONCLUSION}

Stillbirth is one of the most undesirable outcomes of pregnancy. It makes the mother emotionally unstable. The health care provider needs to find a cause for the fetal death and decide on an optimal management strategy. Present study has shown that vaginal birth can be achieved with mechanical and pharmacological methods of induction in most women with IUFD within a reasonable period. Women with previous Caesarean, without any contraindications for TOLAC can be safely offered mechanical ripening followed by pharmacological methods to deliver vaginally. Vaginal birth carries the potential advantages of early recovery and quicker return to daily routine. The current study may aid in counselling women with intrauterine fetal death regarding the mode of delivery and management of future pregnancies to prevent these unfortunate events.

Funding: No funding sources

Conflict of interest: None declared

Ethical approval: The study was approved by the Institutional Ethics Committee

\section{REFERENCES}

1. Blencowe H, Cousens S, Jassir FB, Say L, Cou $\mathrm{D}$, Mathers $\mathrm{C}$ et al. National, regional and worldwide estimates of stillbirth rates in 2015, with trends from 2000: a systematic analysis. Lancet Global Health. 2016;4(2):98-108.

2. Lawn JE, Yakoob MY, Haws RA, Soomro T, Darmstadt GL, Bhutta ZA. 3.2 million stillbirths: epidemiology and overview of the evidence review. BMC Preg Childbirth. 2009;9(1):S2.

3. The Brighton Collaboration Stillbirth Working Group 2015. Available at: http://www.brighton

collababoration.org/internet/en/index/process.html

4. Gynecologists RC. Late intrauterine fetal death and stillbirth. Green-top Guideline. 2010;55:1-33.

5. National Institute for Health and Clinical Excellence. Clinical guideline no.70: Induction of labour. London: National Institute for Health and Clinical Excellence. 2008. Available at HTTP://www.nice.org.uk/nice media/pdf CGO70NICE Guideline.pdf

6. Bugalho A, Bique C, Machungo F, Bergström S. Vaginal misoprostol as an alternative to oxytocin for induction of labor in women with late fetal death. Acta obstetricia et Gynecologica Scandinavica. 1995;74(3):194-8.

7. Chittacharoen A, Herabutya Y, Punyavachira P. A randomized trial of oral and vaginal misoprostol to manage delivery in cases of fetal death. Obstet Gynecol. 2003;101(1):70-3.

8. Nakintu N. A comparative study of vaginal misoprostol and intravenous oxytocin for induction of labour in women with intra uterine fetal death in Mulago Hospital, Uganda. Af Health Sci. 2001;1(2):55-9.

9. WHO recommendations for induction of labour. World health organization.2011. Available at http://apps.who.int /iris / bitstream / 10665 / 44531 / $1 / 9789241501156$ - eng.pdf

10. Nzewi C, Araklitis G, Narvekar N. The use of mifepristone and misoprostol in the management of late intrauterine fetal death. Obstet Gynaecol. 2014;16(4):233-8.

11. Dickinson JE. Misporostol for second trimester termination in women with prior caesarean delivery. Obstet Gynecol.2005;105(2):352-6.

12. Vaginal birth after previous caesarean delivery: Clinical management guidelines for obstetricians and gynecologists. Obstet Gynecol.2004;104(1):203-212.

13. Midred M Ramirez, Sharon Gilbert. Mode of delivery in women with antepartum fetal death and prior cesarean delivery Am J Pernatol.2010; 27(10):825-30.

14. Gardosi J, Kady SM, McGeown P, Francis A, Tonks A. Classification of stillbirth by relevant condition at death (ReCoDe): population-based cohort study. BMJ. 2005;331(7525):1113-7.

Cite this article as: Ajini KK, Reena RP, Radha KR. Management of stillbirths: an observational analysis at a rural tertiary care centre in Kerala, India. Int $\mathbf{J}$ Reprod Contracept Obstet Gynecol 2019;8:1583-7. 